\title{
A Novel Mechanism for Nitric Oxide Production in Nitroalkyl Radicals that Circumvents Nitro-Nitrite Isomerization
}

\author{
Ryan S. Booth, Chow-Shing Lam, and Laurie J. Butler* \\ The James Franck Institute and Department of Chemistry, University of Chicago, Chicago, Illinois 60637, United States
}

\begin{abstract}
In this study, we present a novel mechanism for NO loss from nitroalkyl radicals that circumvents the traditional higher-energy nitro-nitrite isomerization. We characterize the intrinsic reaction coordinate at the B3LYP/6-311++g(3df,2p) level of theory and calculate the transition-state energies using the G4 composite method; the subsequent dynamics en route to the highly exothermic $\mathrm{NO}+$ acetone product channel proceeds through a three-membered ring intermediate. Crossed laser-molecular beam scattering experiments on the 2-nitro-2-propyl radical confirm the importance of this new mechanism in determining the product branching.
\end{abstract}

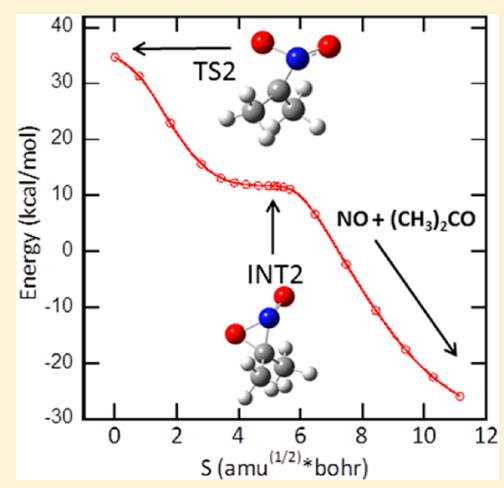

SECTION: Molecular Structure, Quantum Chemistry, and General Theory

$\mathrm{T}$ he decomposition mechanisms of nitroalkanes have been studied experimentally and theoretically for decades because of their relevance to a wide variety of chemistry ranging from atmospheric mechanisms to energetic materials. Nitroalkanes can undergo numerous dissociation events, but two of the most studied are $\mathrm{NO}_{2}$ loss and $\mathrm{NO}$ loss. Loss of $\mathrm{NO}_{2}$ tends to arise from simple $\mathrm{C}-\mathrm{N}$ bond fission, but the production of $\mathrm{NO}$ is not as intuitive. The accepted mechanism for NO loss in nitroalkanes (and other nitroalkyl species) is isomerization to a nitrite intermediate followed by $\mathrm{O}-\mathrm{N}$ bond cleavage; the energetic barrier to this isomerization also tends to be comparable to but higher than $\mathrm{C}-\mathrm{NO}_{2}$ fission. Interestingly, the local geometry (at the $\mathrm{C}-\mathrm{NO}_{2}$ group) of the nitro-nitrite isomerization transition state (TS) is very similar for a series of nitroalkanes, ${ }^{1-6}$ 2-nitropropene, ${ }^{7}$ and nitroaromatics. ${ }^{8}$ Early calculations on the nitro-nitrite isomerization TS in nitromethane were done by Dewar et al. ${ }^{1}$ in 1985. Recently, high-level calculations on this TS in nitromethane are reported in refs 2 and 3 along with high-level energy calculations from previous work. The calculated TSs for nitroalkanes, all on neutral singlet species, all have relatively long ( 1.8-2.2 $\AA$ ) $\mathrm{C}-\mathrm{O}$ and $\mathrm{C}-\mathrm{N}$ bonds; at the TS, these two bonds are usually close to equal lengths. The barrier energies for these TSs are calculated at $62.1 \mathrm{kcal} / \mathrm{mol}$ for 2nitropropane, $64.0 \mathrm{kcal} / \mathrm{mol}$ for nitroethane (this value was originally reported in ref 5 at $60.7 \mathrm{kcal} / \mathrm{mol}$ but recalculated at a higher level of theory), and $67-70 \mathrm{kcal} / \mathrm{mol}$ for nitromethane. ${ }^{2}$ In all of these compounds, simple $\mathrm{C}-\mathrm{NO}_{2}$ bond fission remains at $\sim 60 \mathrm{kcal} / \mathrm{mol}$ and tends to be lower than, or almost equal to, the barrier for nitro-nitrite isomerization. The nitro-nitrite barrier lowers in energy as the number of methyl groups bonded to the $\mathrm{C}-\mathrm{NO}_{2}$ increases. For example, in 2nitropropane, these two barriers are almost equal (within $\sim 1.5 \mathrm{kcal} / \mathrm{mol}$ ), but in nitromethane, the isomerization is much higher $(\sim 10 \mathrm{kcal} / \mathrm{mol})$. Although there are many different calculations for this isomerization in nitroalkanes, there are few calculations done specifically on the corresponding nitroalkyl radical species.

In this study, we demonstrate that the introduction of a radical at the nitroalkyl center unfolds a second mechanism for NO production that is substantially lower in energy than the traditional mechanism. Our calculations at the G4//B3LYP/6$311++\mathrm{g}(3 \mathrm{df}, 2 \mathrm{p})$ level and supporting experiments ${ }^{7}$ show that the 2-nitro-2-propyl radical $\left(\mathrm{CH}_{3} \mathrm{C}\left(\mathrm{NO}_{2}\right) \mathrm{CH}_{3}\right)$ can produce $\mathrm{NO}$ via two distinct pathways. The first pathway is remarkably similar to the aforementioned traditional nitro-nitrite isomerization. For the traditional nitro-nitrite isomerization in nitromethane, the G4 method used here gives a barrier that differs by only $2.5 \mathrm{kcal} / \mathrm{mol}$ from that obtained using high-level multireference configuration interaction. ${ }^{3}$ The geometry of the TS for this path (TS1) is shown in Figure 1 and contains $\mathrm{C}-\mathrm{O}$ and $\mathrm{C}-\mathrm{N}$ bond lengths of $1.94 \AA$ with an energy of $62.5 \mathrm{kcal} /$ mol (corrected for zero-point energy, ZPE). Despite the radical center in the 2-nitro-2-propyl radical, these bond lengths are well within the expected range for a nitro-nitrite isomerization TS but slightly shorter than its analogue in 2-nitropropane (2.2 $\AA$ ). Despite these similarities, the nitrite intermediate exists only as a shoulder on the radical potential energy surface (PES), not a local minimum, whereas nitrite intermediates are all local minima in nitroalkanes. The nitrite intermediate for the radical (INT1) has the standard $\mathrm{C}-\mathrm{O}-\mathrm{NO}$ bonding and is depicted in Figure 1. The intrinsic reaction coordinate (IRC)

Received: December 21, 2012

Accepted: January 24, 2013 


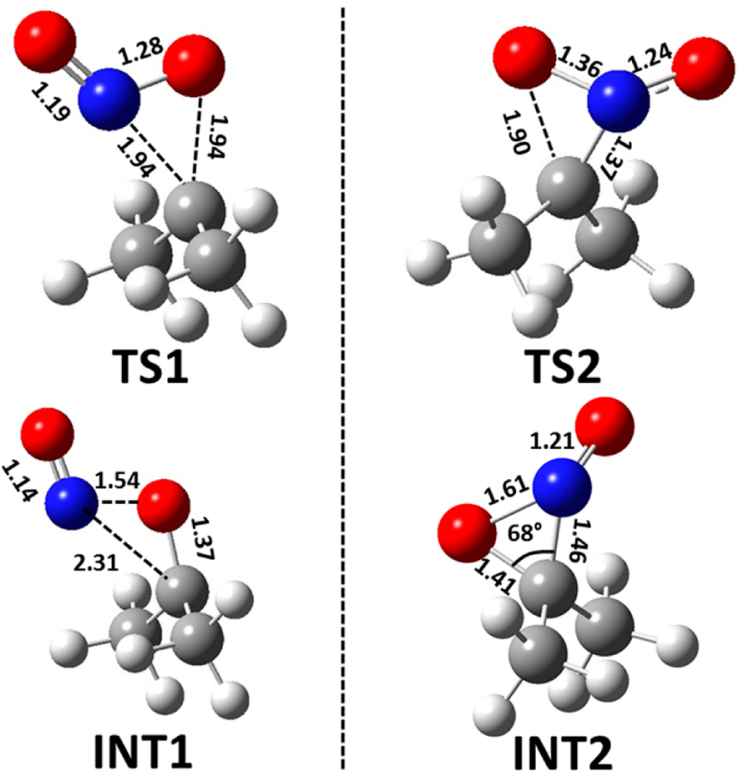

Figure 1. Geometries of the TSs and intermediates (INTs) for both pathways of NO production from the 2-nitro-2-propyl radical. Optimizations were performed at the B3LYP/6-311++g(3df,2p) level. All bond lengths are reported in units of $\AA$.

calculation for this pathway (Figure 2) shows that the reaction does not conclude at INT1 but rather continues on to the NO + acetone products. The high exothermicity of the $\mathrm{NO}+$ acetone products is a consequence of the $\mathrm{C}=\mathrm{O}$ moiety

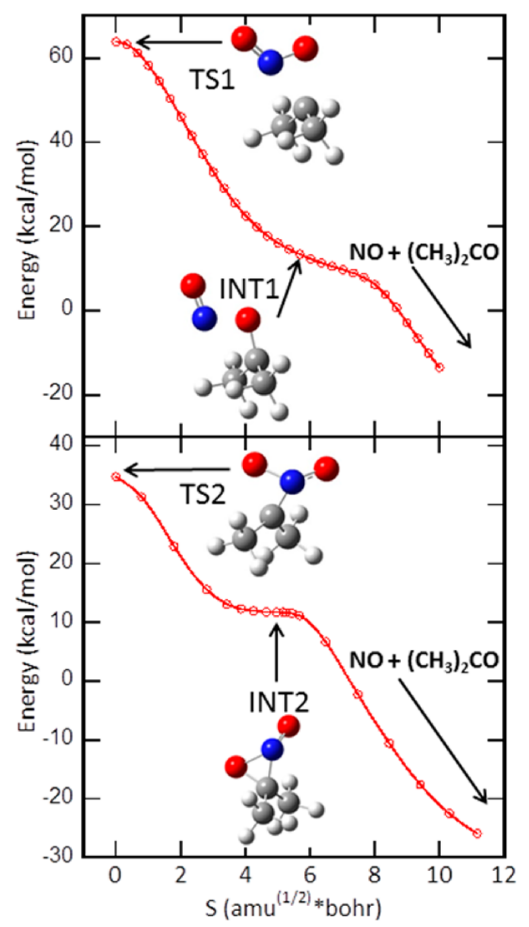

Figure 2. IRC calculations performed at the B3LYP/6-311+ $+\mathrm{g}(3 \mathrm{df}, 2 \mathrm{p})$ level. Top frame: IRC of NO loss via a nitrite intermediate (INT1) from the 2-nitro-2-propyl radical. Bottom frame: IRC of NO loss via formation of a three-membered ring (INT2) from the 2-nitro2-propyl radical. Energy is reported relative to the energy of the $\mathrm{CH}_{3} \mathrm{C}\left(\mathrm{NO}_{2}\right) \mathrm{CH}_{3}$ radical calculated at the B3LYP/6-311++g(3df,2p) level and is not corrected for ZPE. Geometries of the TS and INT are designated on the IRC pathway. forming, which also turns what would have been a local minimum into a mere shoulder.

The second mechanism for NO production has no similarity to the nitro-nitrite isomerization. The TS for this path (TS2) is shown in Figure 1 and has a ZPE-corrected energy of only $35.7 \mathrm{kcal} / \mathrm{mol}$. TS2 has a relatively long $\mathrm{C}-\mathrm{O}$ bond $(1.90 \AA)$ but a short $\mathrm{C}-\mathrm{N}$ bond $(1.37 \AA)$ that is shorter than the $\mathrm{C}-\mathrm{N}$ bond length in the 2-nitro-2-propyl radical of $1.42 \AA$. The most striking difference between TS2 and TS1 is the inequality of the $\mathrm{C}-\mathrm{O}$ and $\mathrm{C}-\mathrm{N}$ bonds. The traditional nitro-nitrite isomerization (TS1) is effectively a rotation of the $\mathrm{NO}_{2}$ group as the $\mathrm{C}-\mathrm{N}$ bond breaks, where the center carbon forms a weak bond with both the $\mathrm{N}$ and $\mathrm{O}$ atoms. In contrast, in the 2-nitro-2propyl radical, the TS for $\mathrm{NO}+$ acetone (TS2) has a weak C$\mathrm{O}$ bond but maintains a $\mathrm{C}-\mathrm{N}$ bond with a bond order higher than one. The IRC calculation for TS2 is shown in Figure 2. Similar to the nitro-nitrite isomerization mechanism, this path also goes through an intermediate (INT2) that is a shoulder rather than a local minimum. In this case, however, the intermediate has a three-membered ring structure that does not exist in saturated nitroalkanes. The geometry of INT2 is detailed in Figure 1 and is illustrated on the corresponding IRC in Figure 2. Again, this intermediate is not a true local minimum along the IRC because moving toward the NO radical product for this mechanism is highly exothermic, and thus, the IRC drops steeply after INT2 due to the formation of the $\mathrm{C}=\mathrm{O}$ bond. Interestingly, contrary to the nitrite isomer, in INT2, the $\mathrm{C}$ atom forms single bonds with both the $\mathrm{N}$ and $\mathrm{O}$ atoms while still maintaining the $\mathrm{O}-\mathrm{NO}$ bond, yielding a threemembered ring. This ring has the expected geometric parameters of a three-center ring with a $\mathrm{N}-\mathrm{C}-\mathrm{O}$ angle of $68^{\circ}$. In order to confirm the presence of a closed cyclic structure, a natural bond order (NBO) analysis was performed at the B3LYP/6-311++g(3df,2p) level for INT2 and every point on the IRC subsequent to its formation. The NBO results confirm that at INT2, there are two-electron bonds between all three atoms involved in the ring and a bond between the $\mathrm{N}$ and the remaining $\mathrm{O}$ atom with a bond order greater than one. As the IRC progresses past INT2, the NBO calculations show electron density transferring from the $\mathrm{C}-\mathrm{N}$ and $\mathrm{O}-\mathrm{NO}$ bonds (on the ring) to the $\mathrm{C}-\mathrm{O}$ and $\mathrm{N}=\mathrm{O}$ bonds. Eventually, this leads to a structure that resembles a ketone moiety interacting loosely with a $\mathrm{N}=\mathrm{O}$ group. However, beyond INT2 along the IRC, the repulsive force (giving a steep downhill slope) is between the $\mathrm{C}$ and the $\mathrm{N}$ atoms rather than between the $\mathrm{N}$ and the $\mathrm{O}$ atoms in INT1.

The significant difference in energy between TS1 and TS2 ensures that TS2 will dominate over TS1 kinetically; therefore, NO loss comes exclusively from the three-membered ring mechanism. Forming TS1 requires substantial stretching of the $\mathrm{C}-\mathrm{N}$ bond and decreases the effectiveness of the radical delocalizing through the $\mathrm{NO}_{2}$ group, thus forcing more radical character on the carbon. This results in a high $(\sim 62 \mathrm{kcal} / \mathrm{mol})$ barrier for nitro-nitrite isomerization. In nitroalkanes, this barrier is near in energy to simple $\mathrm{C}-\mathrm{N}$ bond fission; in contrast, the $\mathrm{C}-\mathrm{NO}_{2}$ bond fission in the 2-nitro-2-propyl radical is actually $15 \mathrm{kcal} / \mathrm{mol}$ higher than TS1 due to the resulting carbene. TS2, however, has a shorter $\mathrm{C}-\mathrm{N}$ bond than the reactant, allowing the radical to shift its delocalization from the planar $\mathrm{C}-\mathrm{NO}_{2}$ moiety in the 2-nitro-2-propyl radical to delocalization into the $\mathrm{C}-\mathrm{N}=\mathrm{O}$ moiety instead. In addition, one of the $\mathrm{NO}$ bonds is now longer than the other, allowing the $\mathrm{O}$ atom to begin forming a $\sigma$ bond with the center $\mathrm{C}$ atom. 
In our extensive experimental investigation of the dissociation dynamics of the 2-nitro-2-propyl radical, ${ }^{7}$ we discovered that this new mechanism for NO loss, from a three-membered ring rather than a nitrite intermediate, competes effectively with all other unimolecular dissociation channels. Specifically, this lower barrier to $\mathrm{NO}$ loss dominated over $\mathrm{NO}_{2}$ loss, effectively suppressing any $\mathrm{NO}_{2}$ production from the radical (our full paper ${ }^{7}$ details a second mechanism for $\mathrm{NO}_{2}$ loss, which is lower in energy than the $\mathrm{C}-\mathrm{NO}_{2}$ bond fission but still cannot compete with $\mathrm{NO}$ loss). This is demonstrated by the lack of signal arising from $\mathrm{NO}_{2}$ loss from the 2-nitro-2-propyl radical in the $m / e=46\left(\mathrm{NO}_{2}^{+}\right)$time-of-flight (TOF) spectrum obtained on our crossed laser-molecular beam scattering apparatus shown in Figure 3. Using momentum conservation, the entirety

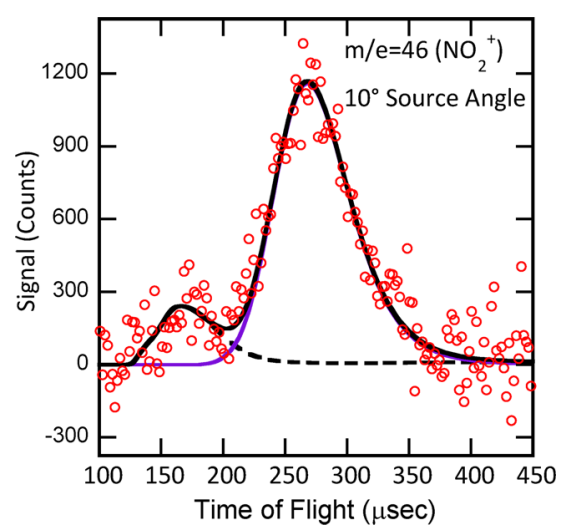

Figure 3. Time-of-flight spectrum taken at $m / e=46, \mathrm{NO}_{2}{ }^{+}$. Data are shown in red circles. The remaining $\mathrm{NO}_{2}$ product from $\mathrm{C}-\mathrm{NO}_{2}$ photofission is fit with the dashed black line. The contribution shown by the purple line is from the dissociation of molecular clusters in the beam. Details for the fits are described in ref 7 .

of the signal from 130 to $200 \mu \mathrm{s}$ is attributed to $\mathrm{NO}_{2}$ fragments arising from primary $\mathrm{C}-\mathrm{N}$ bond photofission in the 2-bromo-2nitropropane precursor. The NO product from the 2-nitro-2propyl radical (via TS2) is shown by the contribution fit by the blue line in the $m / e=30\left(\mathrm{NO}^{+}\right)$TOF (Figure 4). These NO fragments are formed with significant translational energy in this highly exothermic pathway. This channel is the only way of producing fragments with high enough kinetic energies to fit the fast peak in the $m / e=30$ TOF. If TS1 were the only TS leading to $\mathrm{NO}$ production, we would expect extensive generation of $\mathrm{NO}_{2}$ because the barrier to produce $\mathrm{NO}_{2}$ via a 1,2-hydrogen transfer is only $43.4 \mathrm{kcal} / \mathrm{mol}(\sim 19 \mathrm{kcal} / \mathrm{mol}$ lower than TS1). Furthermore, the exceptionally low energy of the barrier of TS2 allows NO loss to compete with HONO elimination. Because the barrier to produce $\mathrm{HONO}$ is merely $31.6 \mathrm{kcal} / \mathrm{mol}$, this channel should dominate over TS1 and $\mathrm{NO}_{2}$ production. In our experimental study, however, we found significant production of both $\mathrm{HONO}$ and $\mathrm{NO}$, which suggests that the barrier to NO production (TS2) is fairly close to 31.6 $\mathrm{kcal} / \mathrm{mol}$.

In this study, we present a novel mechanism for NO loss from nitroalkyl radicals that circumvents the traditional higherenergy nitro-nitrite isomerization. This mechanism can occur in nitroalkyl radical species and has a $\sim 27 \mathrm{kcal} / \mathrm{mol}$ lower barrier than the nitro-nitrite mechanism. This TS maintains a strong $\mathrm{C}-\mathrm{N}$ bond throughout isomerization to a ring structure as opposed to the long $\mathrm{C}-\mathrm{N}$ bonds present in the nitro-nitrite isomerization TSs in nitroalkanes. The lower-energy path does

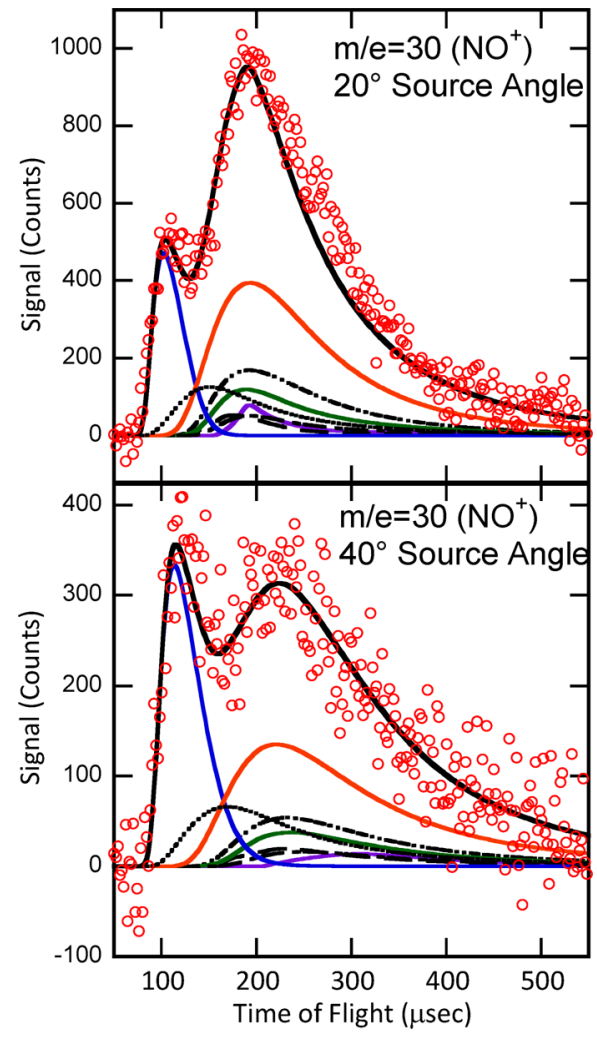

Figure 4. Time-of-flight spectrum taken at $m / e=30, \mathrm{NO}^{+}$at source angles of 20 and $40^{\circ}$ (top and bottom frames, respectively). Data are shown in red circles. The blue fit represents the contribution of NO fragments from the dissociation of $\mathrm{CH}_{3} \mathrm{C}\left(\mathrm{NO}_{2}\right) \mathrm{CH}_{3}$ to $\mathrm{NO}+$ $\mathrm{CH}_{3} \mathrm{C}(\mathrm{O}) \mathrm{CH}_{3}{ }^{7}$ The other contributions are discussed in ref 7. Note that the bottom frame $\left(40^{\circ}\right.$ source angle) was taken at a nozzle temperature of $88{ }^{\circ} \mathrm{C}$.

not pass through a nitrite intermediate but rather forms a threemembered ring involving the $\mathrm{C}, \mathrm{N}$, and $\mathrm{O}$ atoms. In addition, our experimental study on the 2-nitro-2-propyl radical ${ }^{7}$ shows that the addition of this new pathway for producing $\mathrm{NO}$ effectively stifles, due to its extremely low barrier, any $\mathrm{NO}_{2}$ loss. Although this new TS is only available to radicals, it may be applicable to larger energetic materials with geminal dinitro groups whose thermal decomposition mechanisms begin with the loss of one $\mathrm{NO}_{2}$, thus forming nitroalkyl radical centers. This new mechanism for NO loss may be responsible for the production of $\mathrm{NO}$ and release of thermal energy in energetic materials possessing a nitroalkyl radical center due to its extremely low barrier energy and high exothermicity.

\section{EXPERIMENTAL METHODS}

A crossed laser-molecular beam scattering apparatus was used to take the majority of the data presented herein. The methodology is described in detail in the full experimental paper on this system. ${ }^{7}$ Briefly, 2-bromo-2-nitropropane is seeded in helium to a total pressure of 400 Torr and supersonically expanded through a continuous nozzle $(d=$ $0.15 \mathrm{~mm}$ ) heated to $150{ }^{\circ} \mathrm{C}$. The beam passes through two skimmers into the main chamber where it is intersected at a right angle by unpolarized $193 \mathrm{~nm}$ photons from a Lumonics PM-848 excimer laser. The laser is focused to a $\sim 6 \mathrm{~mm}^{2}$ spot with pulse energies of $\sim 2-3 \mathrm{~mJ}$ at the interaction region. Following the photodissociation, any fragments that have a net velocity vector (the vector sum of the molecular beam velocity 
and the velocity imparted during the primary photodissociation and the subsequent dissociation events) within the $1.5^{\circ}$ acceptance angle of an electron bombardment detector travel $45 \mathrm{~cm}$ from the interaction region into the detector. Here, the fragments are ionized via $200 \mathrm{eV}$ electron bombardment. ${ }^{9}$ The ions are accelerated and focused with an electrostatic lens system into a quadrupole mass spectrometer where they are mass-selected and then detected via a Daly detector. ${ }^{10}$ The signal is binned with respect to the total flight time (neutral + ion) in $2 \mu$ s increments and recorded using a multichannel scalar. All TOF spectra presented in this study represent the neutral TOF, where the ion flight time has been subtracted out using the ion flight constant for the apparatus of $4.5 \mu \mathrm{s} \cdot \mathrm{amu}^{-1 / 2}$. The speed distribution of the molecular beam is characterized by sending the beam directly on axis with the detector through a chopper wheel spinning at $300 \mathrm{~Hz}$.

\section{COMPUTATIONAL METHODS}

All energy calculations were performed at the G4//B3LYP/6$311++\mathrm{g}(3 \mathrm{df}, 2 \mathrm{p})$ level $^{11}$ using the Gaussian 09 software package $^{12}$ and corrected for ZPE. The IRC and NBO calculations were performed at the B3LYP/6-311++g(3df,2p) level.

\section{AUTHOR INFORMATION}

\section{Corresponding Author}

*E-mail: L-Butler@uchicago.edu.

\section{Notes}

The authors declare no competing financial interest.

\section{ACKNOWLEDGMENTS}

This material is based upon work supported by the U.S. Army Research Laboratory and the U.S. Army Research Office under contract number W911NF-10-1-0314. Some of the equipment used in the experiment was supported by DURIP-ARO under grant number W911NF-10-1-1049.

\section{REFERENCES}

(1) Dewar, M. J. S.; Ritchie, J. P. Thermolysis of Molecules Containing $\mathrm{NO}_{2}$ Groups. J. Org. Chem. 1985, 50, 1031.

(2) Zhang, C.; Zang, X.; Zhou, M. Isomers and Isomerization Reactions of Four Nitro Derivatives of Methane. J. Comput. Chem. 2011, 32, 1760-1768.

(3) Nguyen, M. T.; Le, H. T.; Hajgató, B.; Veszprémi, T.; Lin, M. C. Nitromethane-Methyl Nitrite Rearrangement: A Persistent Discrepancy between Theory and Experiment. J. Phys. Chem. A 2003, 107, 4286-4291.

(4) Hu, W.-F.; He, T.-J.; Chen, D.-M.; Liu, F.-C. Theoretical Study of the $\mathrm{CH}_{3} \mathrm{NO}_{2}$ Unimolecular Decomposition Potential Energy Surface. J. Phys. Chem. A 2002, 106, 7294-7303.

(5) Wang, Q.; Ng, D.; Mannan, M. S. Study on the Reaction Mechanism and Kinetics of the Thermal Decomposition of Nitroethane. Ind. Eng. Chem. Res. 2009, 48, 8745-8751.

(6) Saha, A.; Kawade, M.; Upadhyaya, H. P.; Kumar, A.; Naik, P. D. Laser-induced UV Photodissociation of 2-Bromo-2-nitropropane: Dynamics of $\mathrm{OH}$ and Br Formation. J. Chem. Phys. 2011, 134, 044316.

(7) Booth, R. S.; Lam, C.-S.; Brynteson, M. D.; Wang, L.; Butler, L. J. Elucidating the Decomposition Mechanism of Energetic Materials with Di-Nitro Functional Groups Using 2-Bromo-2-nitropropane Photodissociation. J. Phys. Chem. A 2012, Submitted.

(8) Hause, M. L.; Herath, N.; Zhu, R.; Lin, M. C.; Suits, A. G. Roaming-Mediated Isomerization in the Photodissociation of Nitrobenzene. Nat. Chem. 2011, 3, 932-937.
(9) Lee, Y. T.; McDonald, J. D.; Lebreton, P. R.; Herschbach, D. R. Molecular Beam Reactive Scattering Apparatus with Electron Bombardment Detector. Rev. Sci. Instrum. 1969, 40, 1402-1408.

(10) Daly, N. R. Scintillation Type Mass Spectrometer Ion Detector. Rev. Sci. Instrum. 1960, 31, 264-267.

(11) Curtiss, L. A.; Redfern, P. C.; Raghavachari, K. Gaussian-4 Theory. J. Chem. Phys. 2007, 126, 084108.

(12) Frisch, M. J.; Trucks, G. W.; Schlegel, H. B.; et al. Gaussian 09, revision A.02; Gaussian, Inc.: Wallingford, CT, 2009. 